Marquette University

e-Publications@Marquette

Biomedical Engineering Faculty Research and

Publications

Biomedical Engineering, Department of

$11-15-2007$

\title{
Mechanical Behavior and Failure Analysis of Prosthetic Retaining Screws after Long-term Use In Vivo. Part 1: Characterization of Adhesive Wear and Structure of Retaining Screws
}

\author{
Youssef S. Al Jabbari \\ King Saud University College of Dentistry \\ Raymond Fournelle \\ Marquette University, raymond.fournelle@marquette.edu \\ Gerald J. Ziebert \\ Marquette University \\ Jeffrey M. Toth \\ Marquette University, jeffrey.toth@marquette.edu \\ Anthony lacopino \\ University of Manitoba
}

Follow this and additional works at: https://epublications.marquette.edu/bioengin_fac

Part of the Biomedical Engineering and Bioengineering Commons

\section{Recommended Citation}

Al Jabbari, Youssef S.; Fournelle, Raymond; Ziebert, Gerald J.; Toth, Jeffrey M.; and lacopino, Anthony, "Mechanical Behavior and Failure Analysis of Prosthetic Retaining Screws after Long-term Use In Vivo. Part 1: Characterization of Adhesive Wear and Structure of Retaining Screws" (2007). Biomedical Engineering Faculty Research and Publications. 550.

https://epublications.marquette.edu/bioengin_fac/550 


\section{Marquette University \\ e-Publications@Marquette}

\section{Electrical and Computer Engineering Faculty Research and Publications/College of Engineering}

This paper is NOT THE PUBLISHED VERSION; but the author's final, peer-reviewed manuscript. The published version may be accessed by following the link in the citation below.

Journal of Prosthodontics, Vol. 17, No. 3 (November, 2007): 168-180. DOI.. This article is ( Wiley and permission has been granted for this version to appear in $\underline{\mathrm{e}}-$ Publications@Marquette. Wiley does not grant permission for this article to be further copied/distributed or hosted elsewhere without the express permission from Wiley.

\section{Contents}

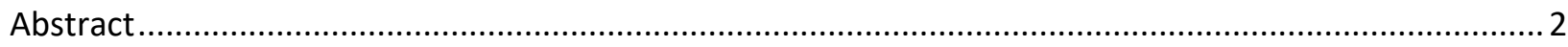

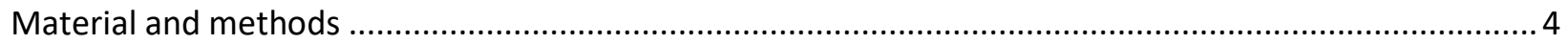

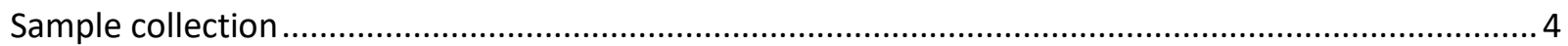

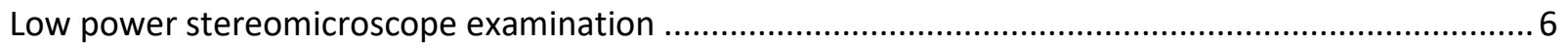

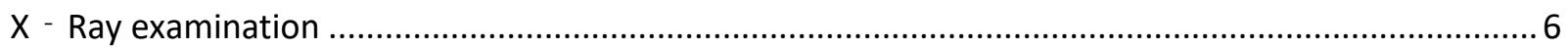

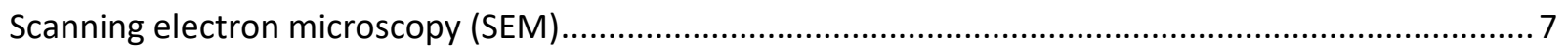

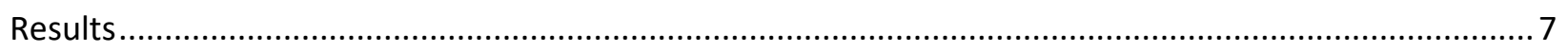

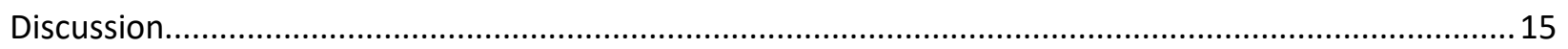

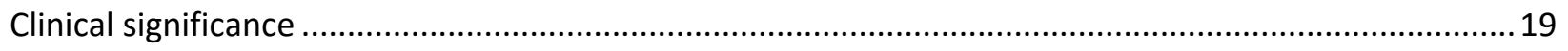

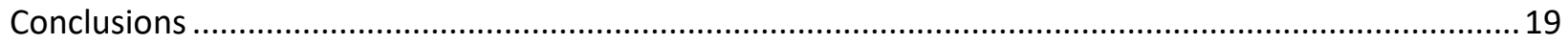

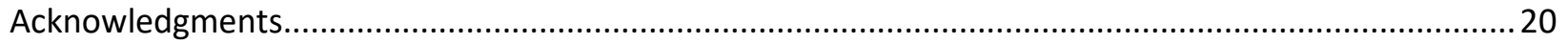

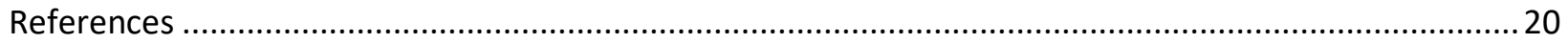




\title{
Mechanical Behavior and Failure Analysis of Prosthetic Retaining Screws after Long- term Use In Vivo. Part 1: Characterization of Adhesive Wear and Structure of Retaining Screws
}

\author{
Youssef S. Al Jabbari \\ Department of Prosthodontic Dental Sciences, King Saud University College of Dentistry, \\ Riyadh, Saudi Arabia
}

Raymond Fournelle

Department of Mechanical and Industrial Engineering, Marquette University School of Engineering, Milwaukee, WI

Gerald Ziebert

Division of Prosthodontics, Marquette University School of Dentistry, Milwaukee, WI

Jeffrey Toth

Division of Dental Biomaterials, Marquette University School of Dentistry, Milwaukee, WI Anthony lacopino

Restorative Dentistry, University of Manitoba of Faculty Dentistry, Winnipeg, Manitoba, Canada

\section{Abstract}

Purpose: The general aim of this study and those presented in Parts 2-4 of this series was to characterize the structure, properties, wear, and fracture of prosthetic retaining screws in fixed detachable hybrid prostheses after long-term use in vivo. This part of the overall investigation addresses whether there are differences in thread wear between the screws closest to the fulcrum and those that are farthest from the fulcrum in fixed detachable hybrid prostheses.

Materials and Methods: The total number of prosthetic retaining screws used in this study was 100 (10 new and 90 used). New screws (controls) from Nobel Biocare (NB) were divided into Group 1 (slotted) and Group 2 (hexed). Ninety used screws (in service 18-120 months) were retrieved from fixed detachable hybrid prostheses in 18 patients ( 5 screws from each patient, 60 from NB and 30 from Sterngold). The used screws were divided into 18 groups. Additionally, each group was subdivided into $A$ and $B$ categories. Category $A$ contained the middle three prosthetic screws, which were considered the farthest screws from the fulcrum line. Category B contained the most posterior two screws, which were 
considered the screws closest to the fulcrum line. All 100 screws were subjected to thorough, nondestructive testing.

Results: Light and scanning electron microscopic examination of all used screws for each group revealed surface deterioration of the active profile of the screw threads consistent with adhesive wear. The observed thread profile deterioration ranged from mild to severe. The wear was aggressive enough to cause galling, which led to thinning of the threads and, in severe cases, to knife-edges at thread crests. In ten groups, the most anterior three screws exhibited more wear than the most posterior two screws. In addition to thread wear, severe plastic deformation was detected on the bottom part of each screw for three groups, and a long external longitudinal crack was detected in one screw of Group 2.

Conclusions: The findings of this study and those presented in Parts 2-4 demonstrate that different retaining screws from the same manufacturer and/or from different manufacturers have different geometrical design, microstructures, major alloy constituents, and microhardness, and that these differences influence their preload and fractured load values. In this part of the overall investigation, the occurrence of galling as a result of wear involving prosthetic retaining screws appears to be an inevitable and unavoidable consequence of long-term use in vivo in fixed detachable hybrid prostheses regardless of the intended/original preload value. The galling rate is greater on the middle three screws compared to the most posterior two screws in fixed detachable hybrid prostheses. The wear pattern is consistent with an adhesive wear mechanism; however, this study does not provide enough data to support a definitive analysis.

In the 40 years since the introduction of osseointegrated implants in the dental field, most of the screw loosening and/or loss of osseointegration (mechanical and/or biological failure) has been attributed to unfavorable biomechanical factors such as occlusal overload and/or poor stress distribution. . $-\mathbf{3}^{-}$Until recently, the fear of abutment and/or prosthetic retaining screws loosening/fracturing remained a major concern for clinicians. ${ }^{4}$ Preloading abutment and prosthetic retaining screws during tightening causes elongation, keeping the screws under tension. This tensile force represents a clamping force between prosthetic implant components and implant fixtures. - It has been suggested that if the torque and preload delivered to the screws are optimal, these forces will minimize screw loosening and fatigue fracture. ${ }^{6}$ Early detection of prosthetic retaining and/or abutment screw loosening requires only a simple retightening to the recommended torque value; however, if screw loosening goes undetected, it will lead to a more complicated, time-consuming, and expensive repair. It has been reported that for implant-retained and -supported (fixed detachable hybrid) prostheses, $31 \%$ of retaining screws were loose at the first follow-up, and an additional $2 \%$ were loose at the second follow-up. $\stackrel{7}{ }$ Other studies have reported $5 \%$ loosening of all retaining screws placed in 91 patients ${ }^{8}$ and loose prosthetic retaining screws in $49 \%$ of treated maxillae and $21 \%$ of treated mandibles at the first annual follow-up. 9

Determination of optimal preload values has been a major concern of dental clinicians and researchers. Various in vitro studies have been performed regarding preload and optimal preload values; however, there have been no in vivo studies to date. Thus, there is a lack of definitive information regarding optimal preload values. A recent study considered the determination of optimum preload to be a complex process, and the investigators stated that "there is no proof that loosening is a result of improper preload." 10 The exact mechanism of retaining screw loosening in fixed detachable hybrid prostheses is likely to be very complex, because it involves fatigue cycling, oral chemical/temperature

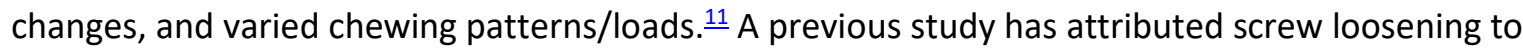


settling effects (short-term relaxation) resulting from loss of contact between the mating threads through adhesive wear of original surface microroughness/asperities leading to preload loss.

The aim of this study was to characterize the wear of prosthetic retaining screws in implant-retained and -supported (fixed detachable hybrid) prostheses after long-term use in vivo. The study addresses the following commonly asked questions:

1 Is there a behavior difference between wear in the screws closest to the fulcrum and those that are farthest from the fulcrum in implant-retained and -supported prostheses?

2 How long do prosthetic retaining screws last before they need to be replaced by new ones in implantretained and -supported prostheses?

\section{Material and methods}

\section{Sample collection}

One hundred implant retaining prosthetic screws were used in this study ( 10 new and 90 used). The 10 new screws (controls) consisted of five slotted and five hexed screws divided into Groups 1 and 2, respectively. The 90 used screws (in service 18-120 months) were retrieved from fixed detachable hybrid prostheses in 18 patients (five screws from each patient, 60 from Nobel Biocare [NB] and 30 from Sterngold [SG]). The used screws were divided into 18 groups. Additionally, each group was subdivided into $A$ and $B$ categories. Category $A$ contained the middle three prosthetic screws, which were considered the farthest screws from the fulcrum line. Category $B$ contained the most posterior two screws, which were considered the screws closest to the fulcrum line. Within each group, screws were designated randomly as $A_{1}, A_{2}$, and $A_{3}$ for category $A$ and $B_{1}$ and $B_{2}$ for category $B$.

Collection of used prosthetic screws was initiated after securing Internal Review Board (IRB) approval and obtaining patient informed consent. Screws were collected from patients treated at Marquette University School of Dentistry (MUSoD) clinics or from office patients treated by MUSoD teaching faculty. Selection criteria for the used screws were as follows: (1) retrieved only from implant-retained and -supported (fixed detachable hybrid) prostheses (minimizes biomechanics force variables among different prosthesis designs); and (2) in service for at least 18 months (assumed to be the minimum time needed to show/detect fatigue cracks and/or thread wear). All screws retrieved represented either NB or SG implant systems.

Table 1 shows the total number of prosthetic screws used in this study and their background data/service history. The collection of used prosthetic screws was completed over a 2-year period, and all retrieved screws were stored in small vials containing methanol at room temperature (to minimize oxidation, which interferes with surface observation). All 100 retaining screws were subjected to nondestructive testing to characterize wear mechanism and structure. 
Table 1. Used prosthetic screws, their background data, and their service history

\begin{tabular}{|c|c|c|c|c|c|}
\hline $\begin{array}{l}\text { Group } \\
\text { number }\end{array}$ & Category & $\begin{array}{l}\text { Number of } \\
\text { screws }\end{array}$ & $\begin{array}{l}\text { Type of screws and } \\
\text { manufacturer }\end{array}$ & $\begin{array}{l}\text { Number of } \\
\text { months in service }\end{array}$ & $\begin{array}{l}\text { Type of opposing maxillary } \\
\text { occlusion }\end{array}$ \\
\hline 1 & $\begin{array}{l}\text { Not } \\
\text { applicable }\end{array}$ & 5 & Slotted (NB) & New (control) & Not applicable \\
\hline 2 & $\begin{array}{l}\text { Not } \\
\text { applicable }\end{array}$ & 5 & Hexed (NB) & New (control) & Not applicable \\
\hline \multirow[t]{2}{*}{3} & $A$ & 3 & Slotted (NB) & 32 & Complete denture \\
\hline & $\mathrm{B}$ & 2 & Slotted (NB) & & \\
\hline \multirow[t]{2}{*}{4} & $A$ & 3 & Hexed (NB) & 120 & Complete denture \\
\hline & $\mathrm{B}$ & 2 & Hexed (NB) & & \\
\hline \multirow[t]{2}{*}{5} & $A$ & 3 & $\begin{array}{l}2 \text { Slotted, } 1 \text { conical } \\
\text { (NB) }\end{array}$ & 27 & Complete denture \\
\hline & B & 2 & Slotted (NB) & & \\
\hline \multirow[t]{2}{*}{6} & $A$ & 3 & Slotted (NB) & 24 & Complete denture \\
\hline & B & 2 & Slotted (NB) & & \\
\hline \multirow[t]{2}{*}{7} & $A$ & 3 & Hexed (NB) & 39 & $\begin{array}{l}\text { Fixed partial denture and } \\
\text { natural teeth }\end{array}$ \\
\hline & B & 2 & Hexed (NB) & & \\
\hline \multirow[t]{2}{*}{8} & $A$ & 3 & Hexed (NB) & 37 & Complete denture \\
\hline & B & 2 & Hexed (NB) & & \\
\hline \multirow[t]{2}{*}{9} & $A$ & 3 & Hexed (NB) & 63 & Complete denture \\
\hline & B & 2 & Hexed (NB) & & \\
\hline \multirow[t]{2}{*}{10} & $A$ & 3 & Slotted (NB) & 30 & Complete denture \\
\hline & B & 2 & Slotted (NB) & & \\
\hline \multirow[t]{2}{*}{11} & $A$ & 3 & Slotted (NB) & 20 & Complete denture \\
\hline & B & 2 & Slotted (NB) & & \\
\hline \multirow[t]{2}{*}{12} & $A$ & 3 & Hexed (SG) & 31 & Complete denture \\
\hline & B & 2 & Hexed (SG) & & \\
\hline \multirow[t]{2}{*}{13} & $A$ & 3 & Hexed (SG) & 18 & Complete denture \\
\hline & B & 2 & Hexed (SG) & & \\
\hline \multirow[t]{2}{*}{14} & $A$ & 3 & Hexed (SG) & 21 & Complete denture \\
\hline & B & 2 & Hexed (SG) & & \\
\hline \multirow[t]{2}{*}{15} & $A$ & 3 & Slotted (NB) & 18 & Complete denture \\
\hline & B & 2 & Slotted (NB) & & \\
\hline 16 & $A$ & $\begin{array}{l}3 \text { (fractured in } \\
\text { two pieces) }\end{array}$ & Hexed (SG) & 20 & Complete denture \\
\hline
\end{tabular}




\begin{tabular}{|c|c|c|c|c|c|}
\hline \multirow[t]{2}{*}{$\begin{array}{l}\text { Group } \\
\text { number }\end{array}$} & Category & $\begin{array}{l}\text { Number of } \\
\text { screws }\end{array}$ & $\begin{array}{l}\text { Type of screws and } \\
\text { manufacturer }\end{array}$ & $\begin{array}{l}\text { Number of } \\
\text { months in service }\end{array}$ & $\begin{array}{l}\text { Type of opposing maxillary } \\
\text { occlusion }\end{array}$ \\
\hline & B & 2 & Hexed (SG) & & \\
\hline \multirow[t]{2}{*}{17} & $A$ & $\begin{array}{l}3 \text { (fractured in } \\
\text { two pieces) }\end{array}$ & Hexed (SG) & 19 & Complete denture \\
\hline & B & 2 & Hexed (SG) & & \\
\hline \multirow[t]{2}{*}{18} & A & 3 & Slotted (NB) & 43 & Complete denture \\
\hline & B & 2 & $\begin{array}{l}1 \text { Slotted, } 1 \text { conical } \\
\text { (NB) }\end{array}$ & & \\
\hline \multirow[t]{2}{*}{19} & A & 3 & Hexed (NB) & 105 & $\begin{array}{l}\text { Implant-retained, tissue- } \\
\text { supported complete denture }\end{array}$ \\
\hline & B & 2 & Hexed (NB) & & \\
\hline \multirow[t]{2}{*}{20} & A & $\begin{array}{l}3 \text { (Fractured in } \\
\text { two pieces) }\end{array}$ & Hexed (SG) & 18 & Complete denture \\
\hline & B & $\begin{array}{l}2 \text { ( } 1 \text { was } \\
\text { fractured) }\end{array}$ & Hexed (SG) & & \\
\hline
\end{tabular}

Study samples (retaining screws) were carefully handled during all stages of analysis and testing, using only plastic tweezers. Prior to testing, screws were placed in a glass beaker containing water and Alconox detergent powder (Alconox, Inc., White Plains, NY) and ultrasonically cleaned for 10 minutes. Each screw was then placed in a different glass beaker containing methanol and ultrasonically cleaned for additional 5 minutes.

\section{Low power stereomicroscope examination}

A low power stereomicroscope Meiji MZS-TR Model (Meiji Techno Co. Ltd., Saitama, Japan) was used for the first phase of nondestructive testing to observe thread wear and/or defects at low magnification. A fiber optic light source, Lumina-I (Chiu Technical Corp., Kings Park, NY), was used for illumination, and white paper was used to provide a neutral background. Prosthetic screws were examined and photographed within a white paper barrel that distributed light evenly, preventing glare. The photography was performed using an Image Analysis System comprised of a Sony CCD digital camera (DXC 151A, Sony, Tokyo, Japan) coupled to a computer. Using Image Pro Plus (4.0) software (Media Cybernetics, Inc., Bethesda, MD), several pictures were taken for selected samples. Each screw was rotated $180^{\circ}$ between observations to ensure that the entire screw was examined.

\section{X-Ray examination}

All screws were evaluated using a microfocus X-ray system (CRX 1000/CRX 2000, CR Technology, Inc., Aliso Veijo, CA) to detect the occurrence of any manufacturing defects in the prosthetic screws. The machine was operated according to the manufacturing instructions: specimens were positioned centrally in the X-ray beam path, and the X-ray beam was slowly brought up and down in Kev and $\mu \mathrm{A}$ until the best image of the sample could be achieved (approximately $65 \mathrm{Kev}$ and $35 \mu \mathrm{A}$ ). 


\section{Scanning electron microscopy (SEM)}

A JEOL JSM 35 scanning electron microscope (JEOL USA, Inc., Peabody, MA) was operated according to manufacturing instructions at $25 \mathrm{Kev}$ using secondary electron imaging. Each screw was rotated $180^{\circ}$ between observations to ensure that the entire screw was examined. The purpose of SEM was to: (1) observe thread wear and/or fatigue crack occurrence; and (2) compare and characterize the thread wear pattern of the middle three screws (category A) and the most posterior two screws (category B).

\section{Results}

Relevant screw terminology used in the following discussion is presented in Figure 1. With reference to this figure, both light microscopy and SEM revealed two types of geometries at the junction area between the screw head and shank for each examined group. As illustrated in Figure 2, one type was characterized by a rounded radius of the junction between the screw head and shank (rounded headshank fillet), whereas the other type was characterized by a wide inclined junction area between the screw head and shank (no head-shank fillet). Rounded head-shank fillets were observed in all retaining screws from NB, whereas the wide inclined junction area was observed in all retaining screws from SG. Additionally, SEM examination revealed two geometrical types of thread roots for each screw examined. In one type, the root of a thread was flat with sharp internal corners, whereas in the other type the root was rounded ( $\mathrm{Fig} 3$ ). The retaining screws from NB demonstrated both geometries; in some groups the roots were flat, while in others the roots were rounded. All examined retaining screws from SG exhibited rounded roots.

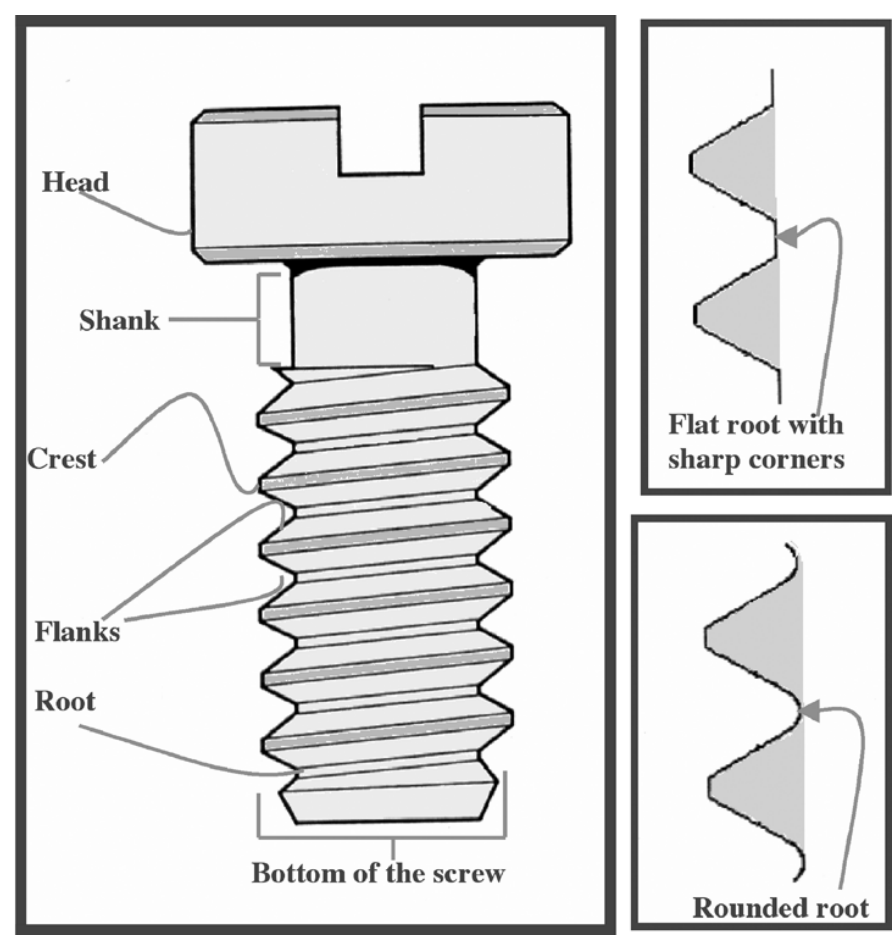

Figure 1

Geometric retaining screw parameters used in the study. 


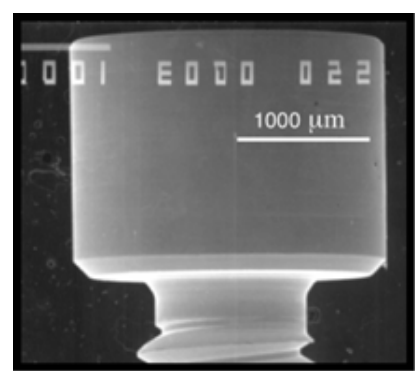

(A)

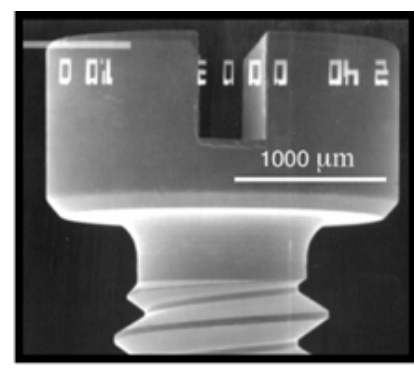

(B)

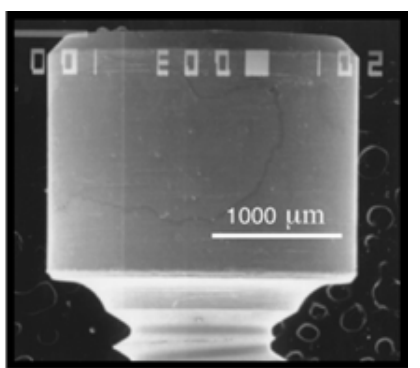

(C)

\section{Figure 2}

SEM micrograph of hexed and slotted retaining screws. (A) and (B) micrographs of hexed (A) and slotted (B) retaining screws for Groups 1 and 2 showing a rounded head-shank fillet. (C) SEM micrograph of a hexed retaining screw from SG $\left(15 B_{1}\right)$ showing a wide inclined junction area between the screw head and shank.

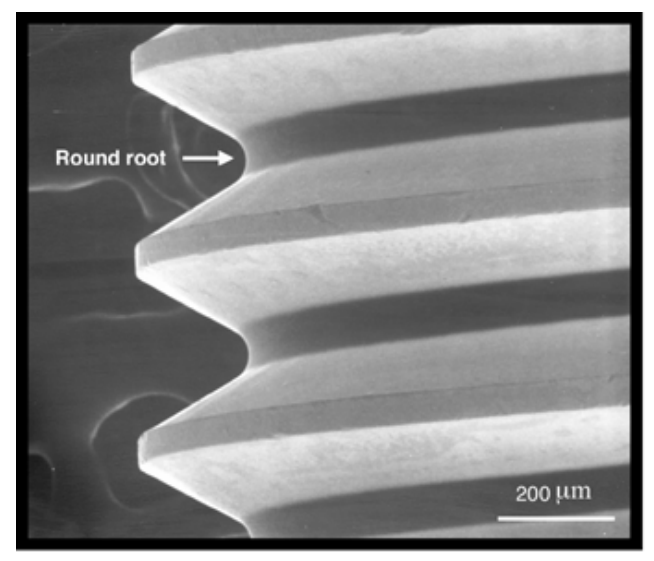

(A)

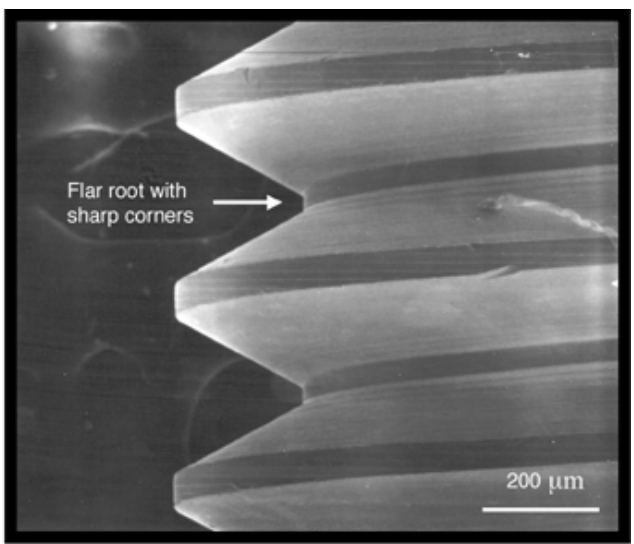

(B)

Figure 3

SEM micrographs of two geometrical designs of the root thread: (A) hexed screw for Group 2 (control); (B) slotted screw for Group 1 (control). Note the nondeteriorated thread profiles of both new screws.

Light and SEM of all used screws for each group revealed surface deterioration of the active profile of the screw threads as a result of what appears to be an adhesive wear mechanism. Under the light microscope, severely deteriorated threads with knife-edge profiles were observed (Fig 4). Under SEM, the wear was aggressive enough to cause galling. Figure 5 illustrates the character of wear in the form of galling for the screws examined. Galling involved both upper and lower flanks and the roots of the threads, which led to thinning of the threads and, in severe cases, to knife-edges at thread crests (tips). The galled surfaces of palladium alloy screws from NB were associated mainly with roughening (Fig 6A), whereas galled surfaces of gold alloy screws from NB and SG showed roughening and/or microscopic material separation in the form of flakes or chips (Fig 6B). 


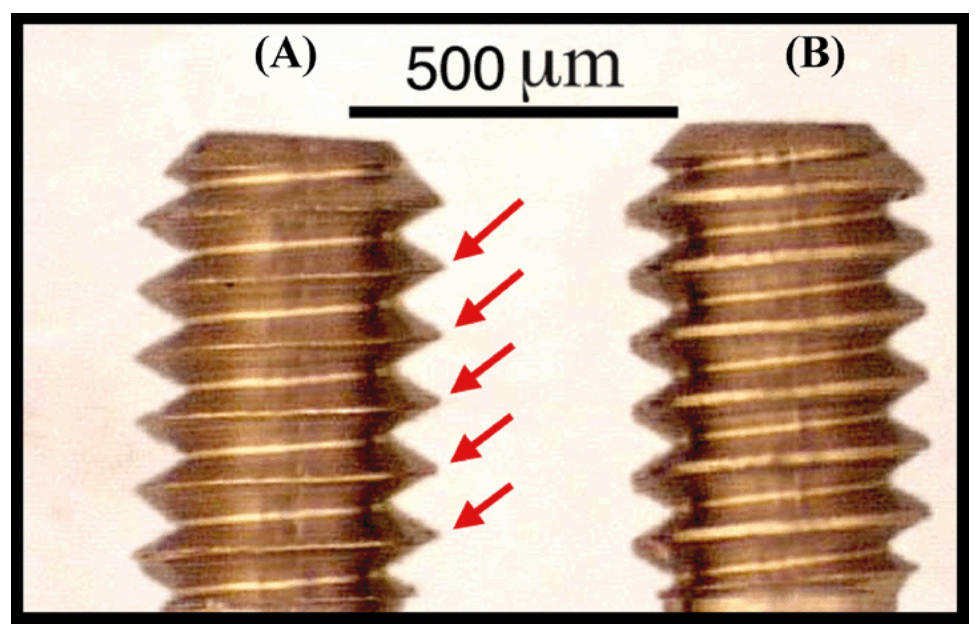

Figure 4

Low magnification view of threaded segment for palladium alloy screws from Group 4 (in service for 10 years): (A) $4 A_{1}$ and (B) $4 B_{1}$. Although the two screws had the same in-service history, (A) shows a knife-edge profile appearance of severely deteriorated threads (arrows).

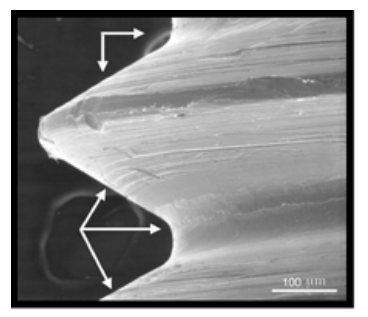

(A)

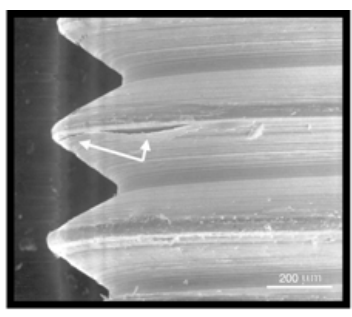

(B)

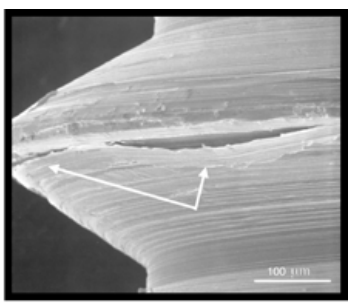

(C)

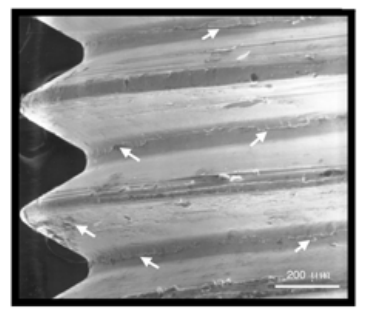

(D)

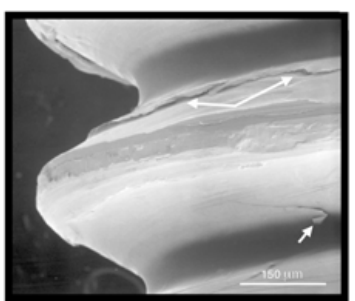

(E)

Figure 5

(A) SEM micrograph of gold alloy screws from NB $\left(8 \mathrm{~A}_{1}\right)$ (in service for 3 years, 1 month). Note that the surface roughening from adhesive wear (galling) occurred on upper and lower flanks and the root of the thread (arrows). Additionally, note the thinning of the thread profiles compared to those in Figure 3. (B) and (C) are SEM micrographs of a gold alloy screw from NB $\left(6 A_{1}\right)$ (in service for 2 years). As in (A), surface roughening from adhesive wear (galling) occurred on upper and lower flanks and in the root of the threads. The lower flank of one thread showed large surface material detachment (arrows). Note the thinning and deterioration of the thread profile. (D) and (E) are SEM micrograph of gold alloy screws from NB ( $5 B_{1}$ and $5 A_{3}$, respectively) (in service for 2 years, 3 months). Arrows indicate flakes or chips formed by galling. 


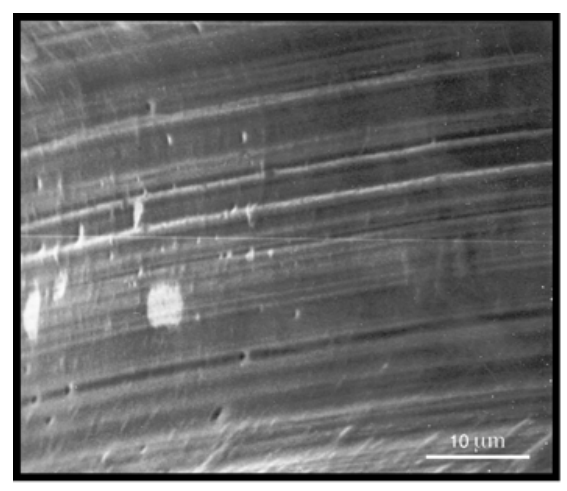

(A)

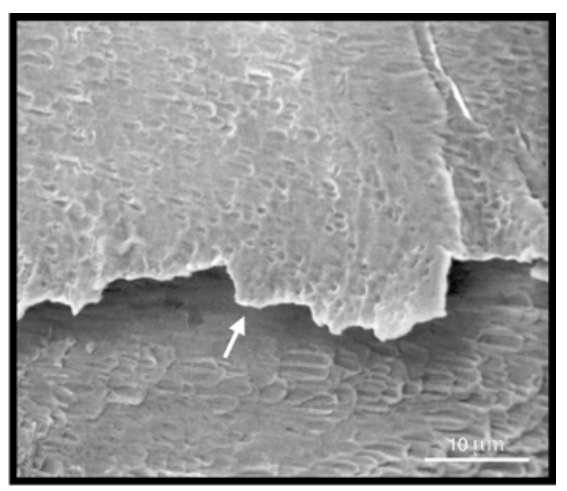

(B)

Figure 6

(A) SEM micrograph of a palladium alloy screw from NB $\left(4 A_{1}\right)$ (in service for 10 years) exhibiting galling, which is associated with surface roughening. (B) SEM micrograps of a gold alloy screw from NB ( $3 A_{3}$ ) (in service for 2 years, 8 months) exhibiting flakes or chips formed by galling (arrow). (original magnification in both (A) and (B) $\times 2000)$.

Additionally, in some gold alloy screws from NB, wear was in the form of what can be described as a "curtain appearance" involving the entire root of a thread (ig 7). The observed thread profile deterioration ranged from mild to severe. Wear in which threads had knife-edge profiles at the thread crest under the light microscope and/or SEM at low magnifications was termed severe. Figure 8 illustrates the observed wear of the retaining screws after they had been in service and demonstrates the transition of thread profiles from normal to moderately thin to severely thin or knife-edge in appearance. This was because screw threads were worn on both upper and lower flanks and in the root areas. As illustrated in Figure 8 , there were variations in thread wear (moderate vs. severe) between screws from the same group with the same in-service history. This difference was mainly due to a newly observed phenomenon in this study. In fixed detachable hybrid prostheses, the most anterior three screws had more wear than the most posterior two screws. The phenomenon was observed in 10 of 18 examined groups. As representative examples, Figures 9 and $\underline{10}$ illustrate this phenomenon for Group 4.

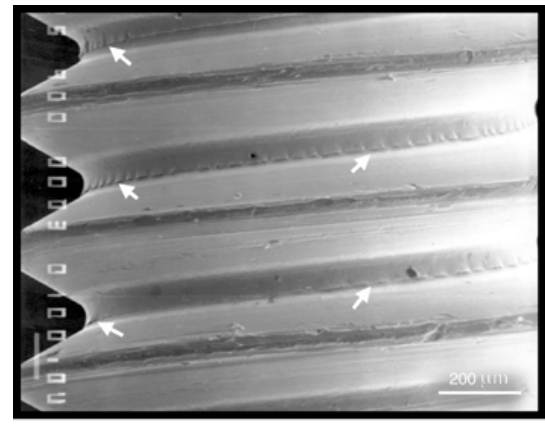

(A)

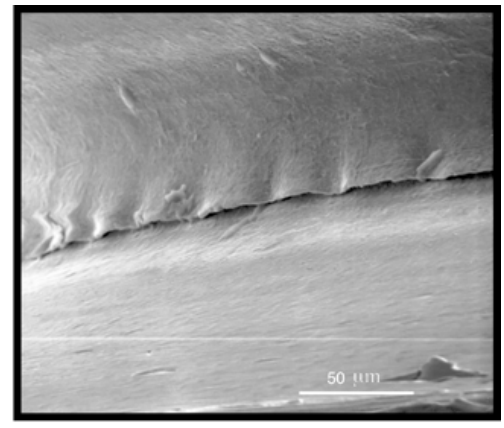

(B)

Figure 7

SEM micrograph of gold alloy screw from NB $\left(10 \mathrm{~A}_{2}\right)$ exhibiting adhesive wear patterns. Note the large galled surface along the root areas in form of a "curtain" (arrows) (original magnification in (A) is $\times 90$ and in (B) is $\times 500)$. 


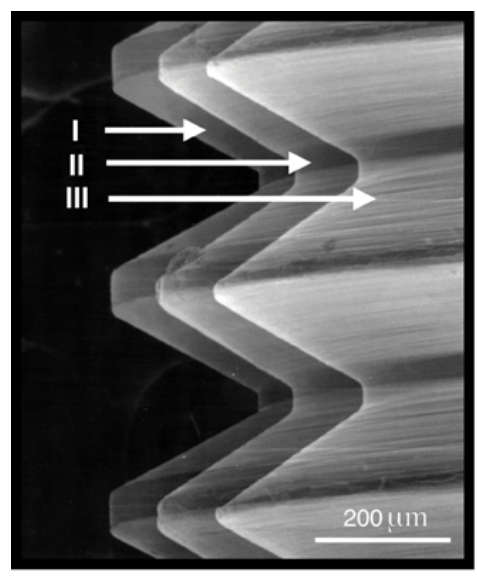

(A)

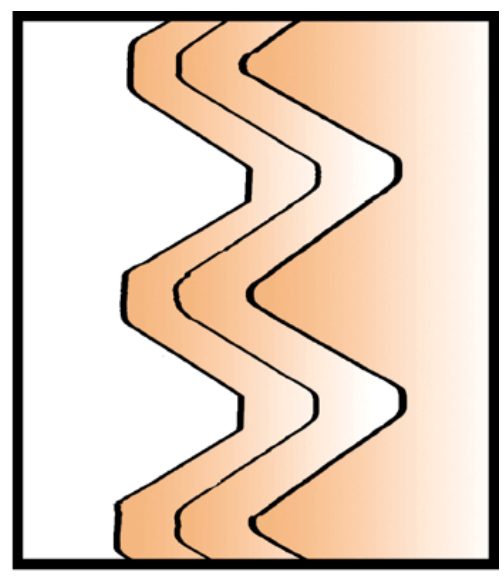

(B)

Figure 8

Adhesive wear of retaining screw threads. (A) Overlapped SEM micrographs at $\times 100$ of thread profiles for: (I) Group $1 \mathrm{~A}_{1}$ (control), (II) $4 \mathrm{~B}_{2}$ (one of two posterior screws), and (III) $4 \mathrm{~A}_{1}$ (one of three anterior screws).

Although the II and III screws had the same in-service history, the most posterior screw showed less thread adhesive wear than the anterior screw. (B) Schematic illustration showing exact outlines of profile of screw threads in (A). Note the development of thread wear and the transition of threads from a normal profile to moderately and severely deteriorated profiles under repeated functional forces in implant-retained and supported prostheses.

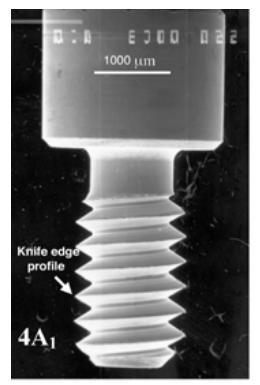

A

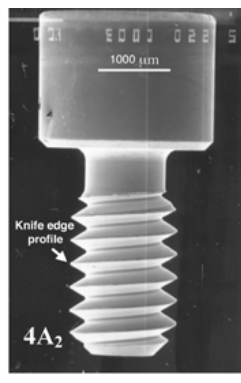

B

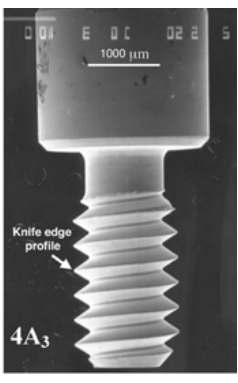

$\mathrm{C}$

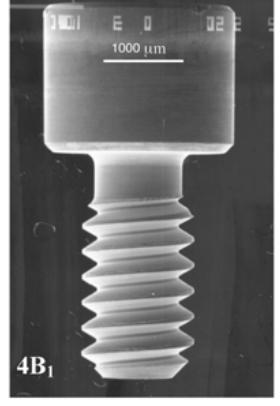

D

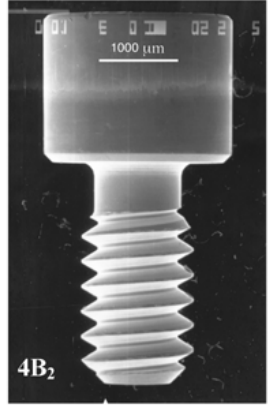

$\mathrm{E}$

Figure 9

SEM micrograph of palladium alloy screws from NB in Group 4 (in service for 10 years). Note severe thread wear (knife-edge profile) of the middle three screws $(A-C)$ compared to moderate thread wear for the most posterior two screws $(D, E)$ (original magnification is $\times 22$ ). 


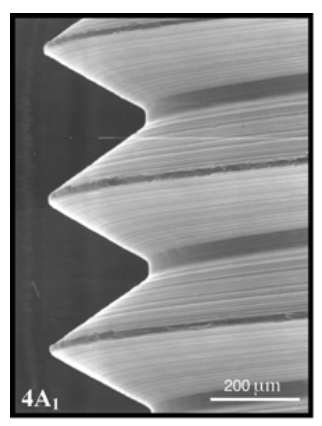

A

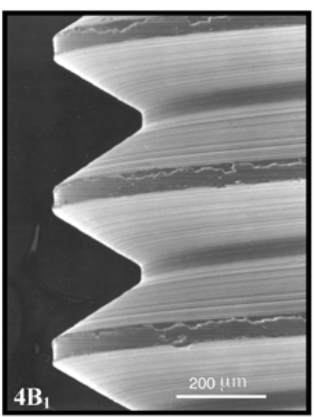

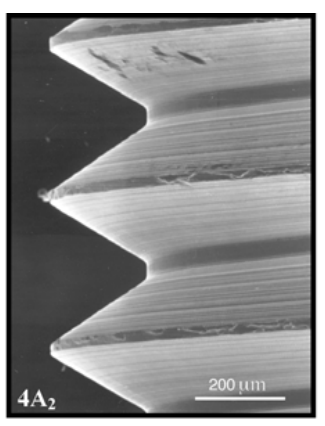

B
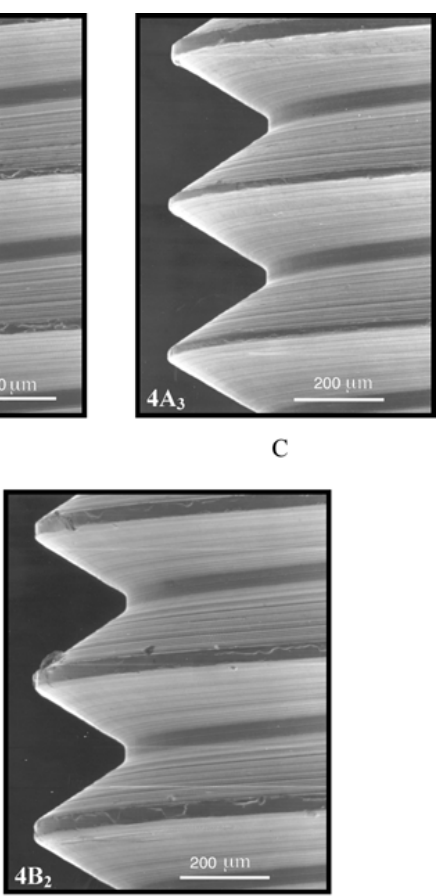

\section{Figure 10}

High magnification $(\times 100)$ SEM of palladium alloy screws from NB in Group 4 shown in Figure 9 (in service for 10 years). Note the severely worn threads of the middle three anterior screws $(A-C)$, whereas the most posterior screws were moderately worn $(D, E)$.

In addition to thread wear, light microscope and SEM examination revealed severe plastic deformation of the bottom part of each screw for Groups 3, 5, and 11, and as an isolated incidence involving only one screw for Groups 6, 8, and 18. The plastic deformation was severe enough to alter the general geometrical appearance of the bottom part and its related threads (Fig 11). The deformation was considered "interference wear," occurring when male threads mate improperly with female threads. Additionally, plastic deformation (surface damage) was observed on the thread crests of some screws examined and, in most of them, the damage was most probably a result of these delicate screws not being carefully handled by clinicians (Fig 12). 


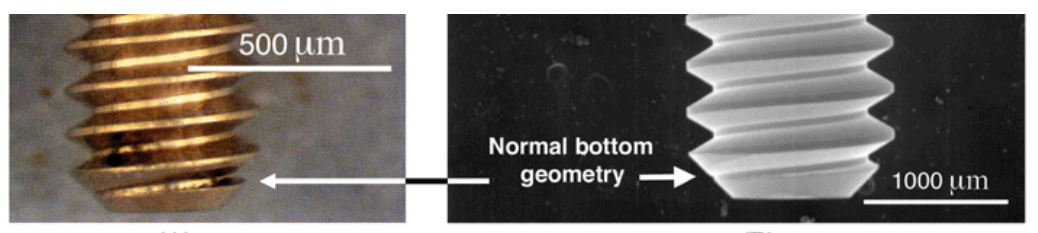

(A)

(B)

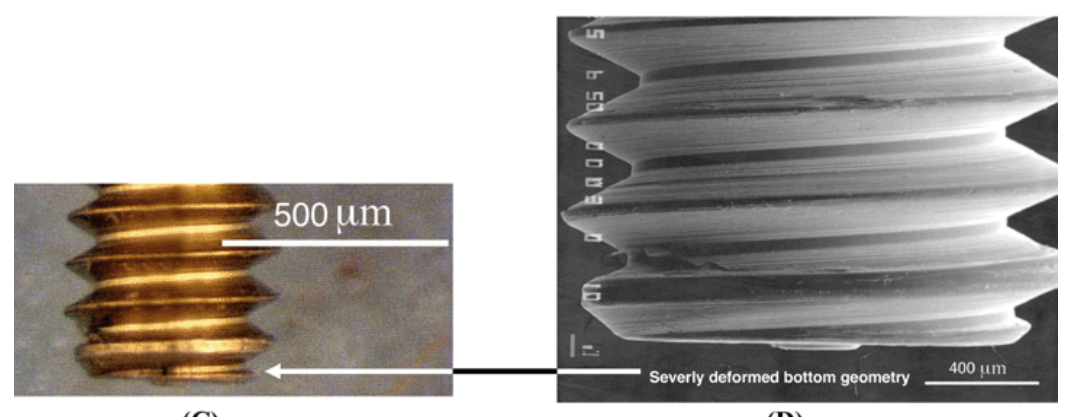

(C)

(D)

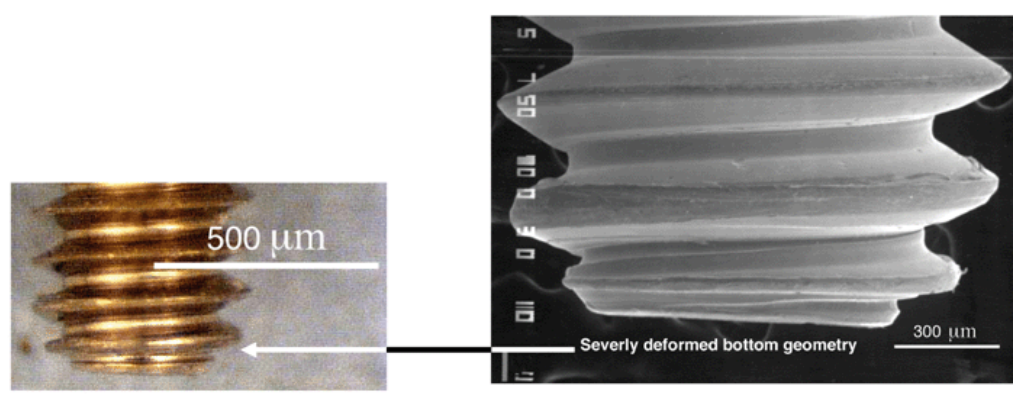

(E)

(F)

Figure 11

Geometrical appearance of the bottom segment of gold alloy screws. (A) and (B) illustrate normal geometrical appearance of the bottom segment of a gold alloy screw from NB in Group 1 (control). (C-F) illustrate the severely deformed bottom segment of the gold alloy screws from NB in Groups 3 ( $C$ and $D$ ) and 6 ( $E$ and F). Original magnification of light stereomicroscope micrographs in $(A),(C)$, and $(E)$ is $\times 48$. Original magnification of SEM micrograph in (B), (D), and (F) are $\times 22, \times 75$, and $\times 65$, respectively.

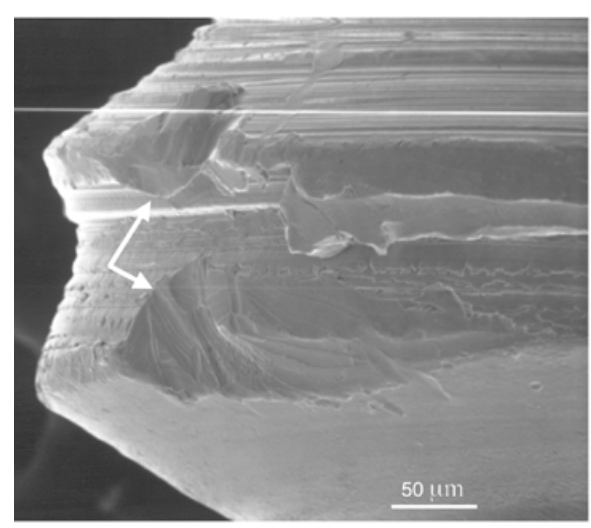

(A)

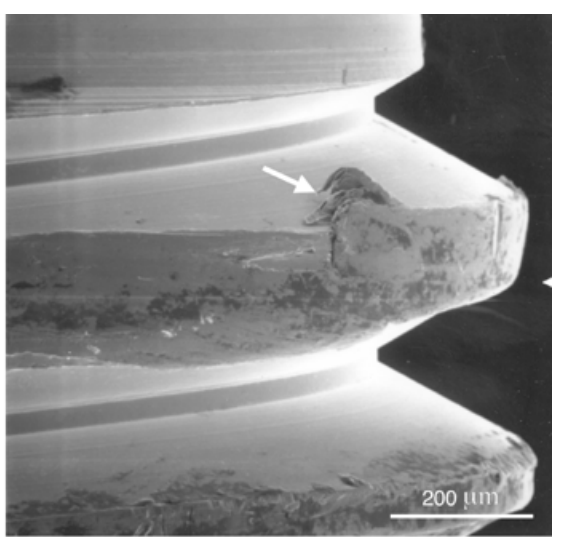

(B)

Figure 12 
SEM micrographs of surface damage or plastic deformation of the thread crest. Defect is noted by arrows. (A) and $(B)$ are SEM micrographs for specimens $5 A_{1}$ and $18 B_{1}$ at $\times 300$ and $\times 120$, respectively.

Fatigue cracks were not detected on the surfaces of the screws examined; however, in one screw of Group $2\left(2 A_{1}\right)$, an external crack was observed. The crack extended almost the full length of the screw along the screw axis. It started at the shank area as a large, wide crack and extended down to the threaded segment (the body and bottom) of the screw as a hairline crack (Figs 13 and 14). The crack appeared ragged and irregular and was generally discontinuous. The crack was considered to be a "seam" (an unfused fold or lap), which originated during original casting solidification. $\underline{12}$ Surprisingly, the screw served for 10 years clinically in the patient's mouth with no fatigue and/or premature failure.

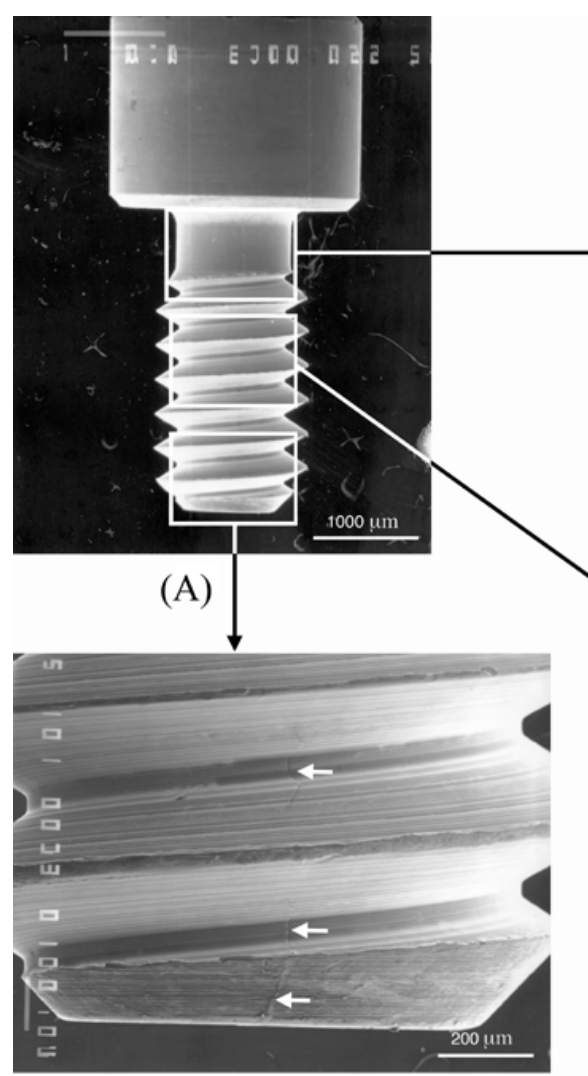

(D)

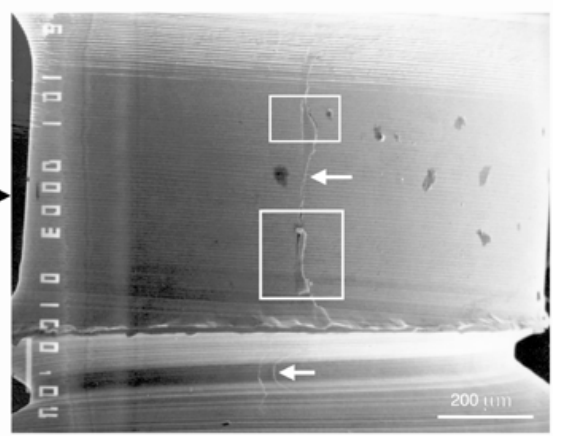

(B)

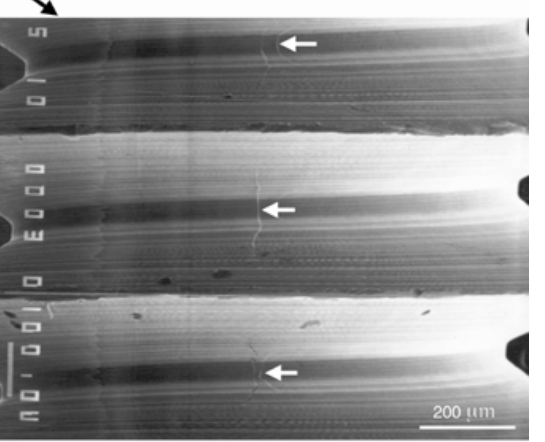

(C)

Figure 13

SEM micrographs of a palladium alloy screw from NB in Group 4 ( $\left.4 \mathrm{~A}_{1}\right)$ (in service for 10 years). Note the external crack-like defect (seam) along the entire length of the screw as indicated by arrows. Outlined three areas in $(A)$ at $\times 25$ are shown in (B-D) at $\times 100$. The outlined two areas in (B) are shown in Figure 14. 


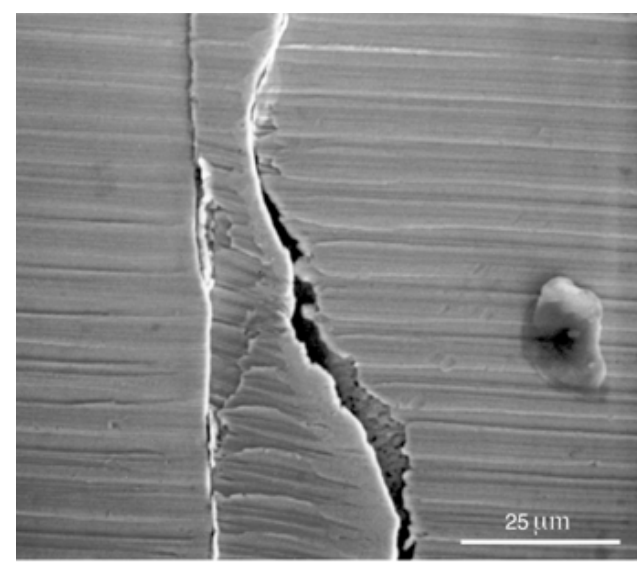

(A)

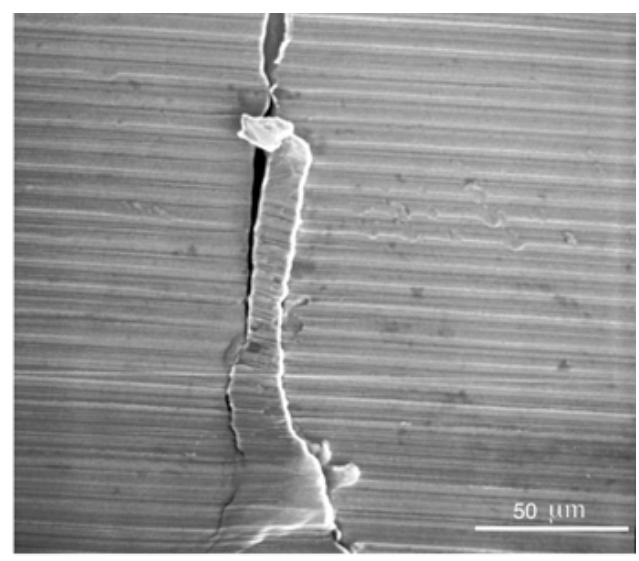

(B)

Figure 14

SEM micrograph of the screw defect. SEM micrograph of the two outlined areas in Figure 13B showing the external crack-like defect at the shank area. Original magnifications in (A) and (B) are $\times 1000$ and $\times 500$, respectively.

Lastly, no internal defects (voids) were detected in any of the screws examined, suggesting that the occurrence of casting porosity/volumetric defects in retaining screws should be considered uncommon.

\section{Discussion}

To date there is a lack of knowledge regarding mechanical behavior of prosthetic implant components after long-term use in vivo. Such knowledge is essential for predictable long-term outcomes. This study examined the wear of prosthetic retaining screws resulting from long-term use in vivo. Our observations are consistent with an adhesive wear mechanism. Adhesive wear is defined as "the removal or displacement of material from a surface by the welding together and subsequent shearing of minute areas of two surfaces that slide across each other under pressure." 13 On any threaded fastener, the negative consequences of adhesive wear are: (1) thread disengagement; (2) screw loosening; (3) preload reduction; and (4) fatigue failure. Therefore, we believe that the clinicians should consider the observed wear on retaining screws a serious issue.

The proposed adhesive wear mechanism for the retaining screws observed in this study is based on: (1) microscopic observations of wear patterns; (2) fixed detachable hybrid prostheses biomechanics; and (3) threaded fastener mechanics. After the first torquing of the retaining screw to clamp the prosthesis and implant fixtures, the primary force in the screw shank is tension, whereas the main stresses in the screw threads are shear stress parallel to the thread surfaces and compressive stress normal to them. $\underline{\underline{14}}$ The tension force is created by stretching the screw during tightening, while the shear and compressive stresses are created by intimate contact between the upper flank of retaining screw threads (male) and the lower flanks of abutment screw threads (female). At this stage, initial adhesive wear occurs upon the sliding of thread flank surfaces when torque forces are applied, leading to plastic deformation and more

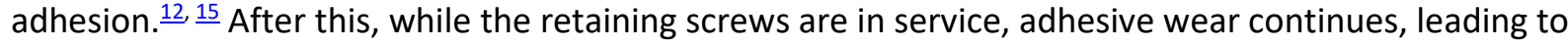
galling with the sliding surfaces welding together and large areas in the form of flakes or wafers pulling away from the surface (igs 4-10). Galling is considered an advanced stage of adhesive wear, defined as 
"a condition whereby excessive friction between two mating surfaces results in localized welding with a further roughening of the rubbing surfaces of one or both of the two mating parts." $\underline{13}$

It appears that wear of retaining screws is a slow, unavoidable, and undesirable process in fixed detachable hybrid prostheses caused by complex repeated functional (bite) forces. The complexity of the bite force is due to the complex motion of the mandible and the inclination of the tooth cusps, which induce a combination of vertical and horizontal forces. ${ }^{.}$These forces might be exaggerated in fixed detachable hybrid prostheses because of the cantilever. The observed wear in this study may be referred to as a "long-term relaxation phenomenon" of the retaining screw. No previous studies examined in-service behavior of implant abutment and/or prosthetic retaining screws; however, the proposed adhesive wear mechanism is supported by the general belief among engineers that the fastener subjected to shock/vibration or thermal cycles will not lose all preload immediately, but will first undergo a relatively slow loss of preload. $\stackrel{14}{ }$ The process of loosening has been described as occurring in two stages. First, there is minute slippage between the mating male/female threads when repeated load is applied to the screw joint causing initial preload loss. Next, when sufficient preload value has been lost by repeated load and vibration, the mating threads start to turn.14 Even though the occurrence of progressive preload loss has been documented, the cause remains unknown. One theory suggests that when the friction between two mating male/female threads gets too low, the fastener will "slide down" the inclined flanks of the threads. Accordingly, the fastener will lose more preload under repeated external force/vibration. The vibration of a fastener will "hammer down" the thread surfaces, leading to more adhesive wear and loss of preload. $\underline{14}$ The observation of the location of adhesive wear on the upper and lower flanks and the root of a thread is consistent with observations that "thread stripping in fasteners occurs at their pitch diameter and roots." $\underline{14}$

Severe wear was observed in this study, as evidenced by the knife-edge appearance of the thread profile. If this wear goes undetected, it will lead to serious and undesirable consequences. As shown schematically in Figure 15, severely worn threads (with knife-edge profiles) will reach this stage without alteration in their original length. If they continue in service, they will become shorter and shorter with time, resulting in what is called "thread stripping." If the engagement length is too short, too few threads support the load, and thread flank mating areas are smaller than those intended by the manufacturer, causing excessive relaxation and preload loss. $\underline{14}$ 


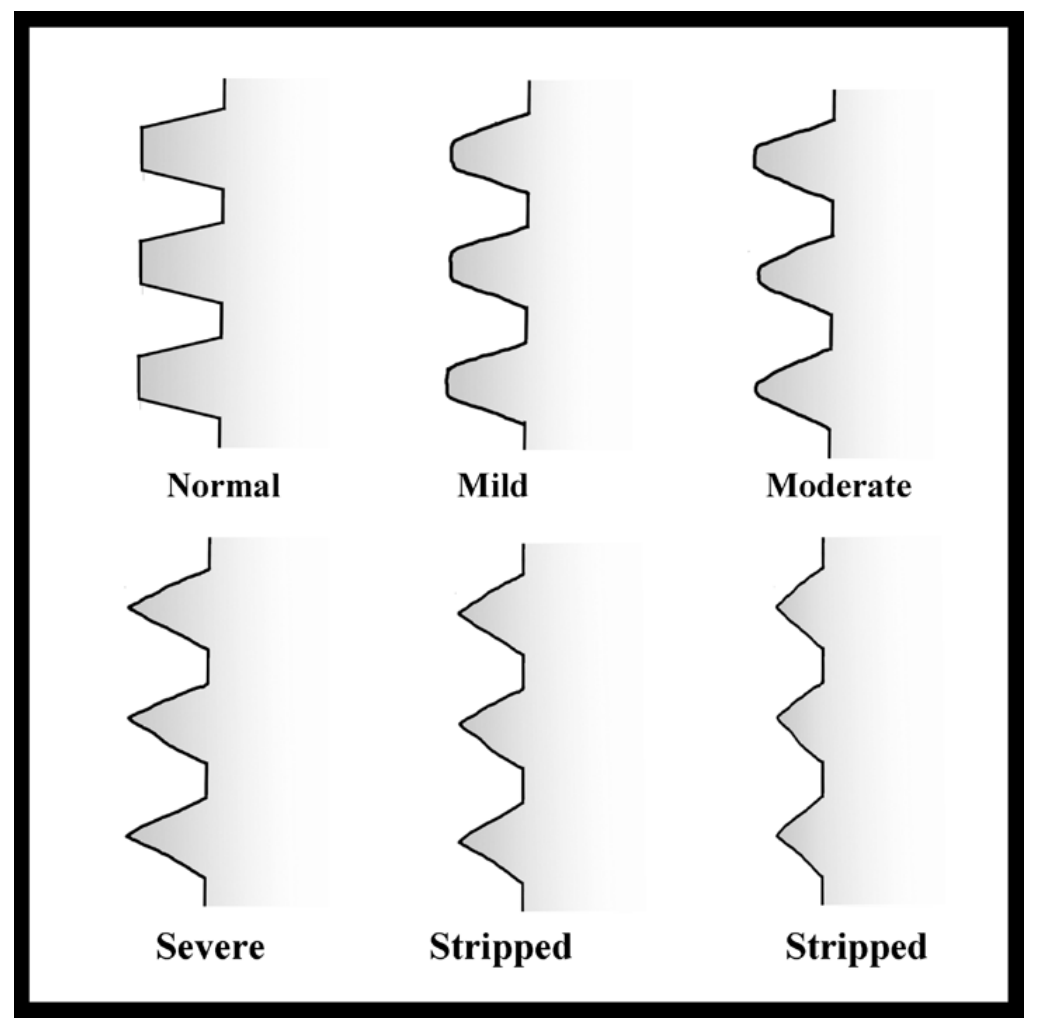

Figure 15

Schematic diagram of the mechanism of adhesive thread wear of prosthetic retaining screws in implantretained and -supported prostheses. Severely worn threads, if kept in service, will become short, leading to what is called "thread stripping." Thread stripping means too few threads support the load, and thread flanks mating areas are smaller than those intended by the manufacturer, causing excessive relaxation and preload loss.

Based on the observed thread wear, one may question whether female threads of the abutment screw demonstrate similar in-service behavior. If the female threads are significantly harder than the material from which the male threads were made, the wear will involve only the prosthetic retaining screw threads. If, on the other hand, the male thread material is harder, the wear will involve only the abutment screw thread. If both materials have equal hardness, both abutment and prosthetic retaining screws will wear simultaneously at an equal rate. $\underline{\underline{14}}$

In this study, thread roots of retaining screws were of two forms: rounded and flat with internal sharp corners. It has been suggested that the thread roots with internal corners are considered natural places for initiation of fatigue cracks, and using threads with radiused (rounded) roots might increase fatigue life; $\underline{\underline{14}}$ however, this study found no in-service behavior differences between the two forms. Both showed no sign of fatigue cracks.

With respect to how long prosthetic retaining screws will last before they need to be replaced by new ones, it is not possible to predict exactly how many years these screws will last. It has been assumed that with optimal preload value and accurate fit of the implant prosthesis, the life of a retaining screw should be 20 years; $\underline{17}$ however, this study demonstrates that adhesive wear (galling) occurs at a faster rate than previously believed. Screws with severe thread deterioration/wear (knife-edge profile) were 
observed after only 4-10 years in service. Thus, it is proposed that the life of retaining screws used with fixed detachable hybrid prostheses should be considered as 10 years; however, the life of the retaining screws might be prolonged to 20 years if clinicians follow a regular maintenance protocol. Regardless of the adequacy of the initial preload value, under repeated functional forces, galling and gradual preload loss is a fact in the oral cavity. The only way to minimize galling is through retorquing of the screws.

One unexpected finding of this study was the severe deformation of the bottom part of prosthetic retaining screws and their related threads. The deformation occurred in all retaining screws of three groups (Groups 3, 5, and 11) and an isolated single screw of another three groups (Groups 6, 8, and 18). Such deformation will reduce the amount of contact between male and female threads, minimizing the final intended preload. Additionally, the deformation will change the original geometry of the threads, which may result in improper engagement and loss of thread strength. The deformation that involved all screws of one group was believed to be caused by misfit of the prosthesis framework superstructure. Misfit of the superstructure can cause misalignment between the hole of the upper gold cylinder and the lower female abutment screw. It has been suggested that geometrical screw deformation might occur as a result of a small degree of misfit, such as the one occurs when the screw hole in the prosthesis does not align with that in the abutment. 6 Based on engineering fastener mechanics, misfit absorbs part of the torque forces, thus reducing the final amount of torque available to create optimal preload (clamping force) between joint members..$^{14}$ Unfortunately, a true "passive fit" of a fixed detachable hybrid prosthesis superstructure to its implant abutments seems unattainable intraorally and, until recently, it was not known what degree of misfit leads to complications. $\frac{18}{\text { Therefore, the }}$ finding of this study may provide important clinical information regarding: (1) the level of misfit that is clinically important, beyond which damage is likely to occur; and (2) how one measures misfit in a clinical situation. A recent opinion has stated that these issues "currently are unanswered and should be the focus of a high priority research effort." 19

The occurrence of severe deformation in a single screw of one group was thought to be caused by clinicians as a result of improper alignment of the retaining screw to the hole of the abutment screw. It has been found that torque application on the retaining screw can be compromised by restricted deep access holes and poor visibility. $\underline{\underline{20}}$ Observation of scratches and plastic deformation on the top surface of screw heads (probably caused by the torque wrench) can be considered an additional indication of poor visibility. Therefore, the clinician is a very important factor affecting the final torque-preload relationship.

In this study, it was observed that the middle three screws demonstrated higher thread wear than the two most posterior screws in the majority of examined groups. In fixed detachable hybrid prostheses, the typical arch configuration is supported anteriorly by implant fixtures and posteriorly has an extended cantilever. It has been hypothesized that the introduction of cantilever forces might increase the maximum load per screw from one and one-half to two times the applied load. $\underline{21}$ It has also been proposed that the most anterior fixtures (farthest from the fulcrum) are subjected mainly to tensile forces, while the most posterior fixtures (closest to the fulcrum) are subjected mainly to compressive forces. $\frac{16}{-}$ Accordingly, as the tendency of tensile forces is to separate clamped joints, it would be of greater concern for anteriorly-located implant fixtures in implant-retained and -supported prostheses. With respect to whether there is any mechanical behavior difference between the screws closest to the fulcrum and those that are farthest from the fulcrum in fixed detachable hybrid prostheses, this study suggests there is. Annual rotation of retaining screws as part of a maintenance protocol will redistribute effects of repeated functional forces on all prosthetic retaining screws. 


\section{Clinical significance}

It is possible that due to increased demand for esthetics and/or simplicity by both clinicians and patients, the future of the prosthetic retaining screw will meet a fate similar to the gold foil restoration; $\underline{22}$ however, this study may still be considered significant because of the many existing restorations using implant retaining screws. Until very recently, dental cements were not recommended to be used for retention in fixed detachable hybrid prostheses. ${ }^{23}$ Even now, the use of cement for retention is primarily restricted to fixed partial dentures and single-tooth restorations supported by implants.

Prosthetic retaining screws are like hardware parts on any equipment, requiring periodic check-up, maintenance, and replacement. In this study, the observed deterioration of retaining screw thread profile and occurrence of galling were greater than what was expected. Therefore, the following is a suggested maintenance and check-up protocol to minimize and/or delay adhesive wear (galling) and thread profile deterioration in retaining screws of fixed detachable hybrid prostheses:

1 It has been suggested to retorque retaining screws after the first year in service to compensate or overcome screw embedment/settling effects (short-term relaxation).24 Based on this study, it is highly recommended that clinicians retorque retaining screws after the first 6 months of service using the manufacturer's torque wrench. After this initial adjustment, it is advisable to retorque retaining screws annually.

2 Similar to rotation of car tires after a prescribed number of miles to minimize and redistribute wear, it is highly advisable to rotate the middle screws with the posterior screws. This can be done once a year and at the same time clinicians perform the previously suggested retorquing step.

3 Clinicians who provide implant treatment extensively should have a light stereomicroscope (magnifier) in their office to evaluate retaining screws and screw thread profiles annually at the time when they perform screw rotation replacing any severely damaged screws. They should also look for any screw deformation, especially in the bottom part of the screws. If clinicians detect severe plastic deformation involving all retaining screws of the hybrid prosthesis, they should consider a lack of passivity of prosthesis fit. This may involve remaking the metal superstructure and/or the entire prosthesis.

\section{Conclusions}

From this study it can be concluded that:

1 The occurrence of galling as a result of adhesive wear involving prosthetic retaining screws may be considered an inevitable and unavoidable consequence of long-term use in vivo in fixed detachable hybrid prostheses regardless of the intended (original) preload value.

2 The galling (adhesive wear) rate appears to be greater on the middle three screws compared to the most posterior two screws in fixed detachable hybrid prostheses.

3 The geometrical deformation of all the screws of a fixed detachable hybrid prosthesis may indicate framework superstructure misfit.

4 The occurrence of significant manufacturing defects on prosthetic retaining screws, which might adversely affect their mechanical properties and behavior, should be considered uncommon.

Lastly, as the findings of this study are based on qualitative observation, future quantitative study designs are required for definitive analysis. Measurements can be recorded to determine the actual 
dimensions of screw thread diameters before and after long-term use in vivo. In this case, the exact and average amount of metal wear can be determined per year of service. This will facilitate prediction of lifespan of implant retaining screws.

\section{Acknowledgments}

The authors thank Dr. Charles Goodacre for his valuable input during the writing of this manuscript. The authors also thank Jim Brozek for his assistance in formatting the photographs and illustrations.

\section{References}

1 McGlumphy EA, Robinson DM, Mendel DA: Implant superstructures: a comparison of ultimate failure force. Int J Oral Maxillofac Implants 1992;7:35-39

2 Rangert B, Krogh PH, Langer BM, et al: Bending overload and implant fracture: a retrospective clinical analysis. Int J Oral Maxillofac Implants 1995;10:326-334

3 Kallus T, Bessing C: Loose gold screws frequently occur in full - arch fixed prostheses supported by osseointegrated implants. 1994;9:477-484

4 Martin WC, Woody RD, Miller BH, et al: Implant abutment screw rotations and preloads for four different screw materials and surfaces. J Prosthet Dent 2001;86:24-32

5 Haack JE, Sakaguchi RL, Sun T, et al: Elongation and preload stress in dental implant abutment screws. Int J Oral Maxillofac Implants 1995;10:529-536

6 Burguete RL, Johns RB, King T, et al: Tightening characteristics for screwed joints in osseointegrated dental implants. J Prosthet Dent 1994;71:592-599

7 Jamt T: Failure and complications in 391 consecutively inserted fixed prostheses supported by Branamark implants in edentulous jaws. A study of treatment from the time of prosthesis placement to the first annual checkup. Int J Oral Maxillofac Implants 1991;6:270-276

8 Naert I: A study of 589 consecutive implants supporting complete fixed prostheses. Part II: prosthetic aspects. J Prosthet Dent 1992;68:949-956

9 Jemt T, Linden B, Lekholm U: Failure and complication in 127 consecutively placed fixed partial prostheses supported by Branemark implants: from prosthetic treatment to first annual checkup. Int J Oral Maxillofac Implants 1992;7:40-44

10 Jaarda MJ, Razzoog ME, Gratton DG: Effect of preload torque on the ultimate tensile strength of implant prosthetic retaining screws. Implant Dent 1994;4:17-21

11 Sakaguchi RL, Borgersen SE: Nonlinear contact analysis of preload in dental implant screws. Int J Oral Maxillofac Implants 1995;10:295-302

12 Failure analysis and prevention. ASM Handbook, volume 11, 4th printing. Materials Park, OH , ASM, 1992

13 Friction, lubrication and wear technology. ASM Handbook, volume 18, 4th printing. Materials Park , $\mathrm{OH}, \mathrm{ASM}, 1992$

14 Bickford JH: An Introduction to the Design and Behavior of Bolted Joints, (ed 3). New York, NY, Marcel Dekker, Inc., 1995

15 Jorneus L, Jemt T, Carlsson L: Loads and designs of screw joints for single crowns supported by osseointegrated implants. Int J Oral Maxillofac Implants 1992;7:353-359

16 Rangert B, Jemt T, Joreous L: Forces and moments on Branem - ark implants. Int J Oral Maxillofac Implants 1989;4:241-247 
17 Patterson EA, Johns RB: Theoretical analysis of the fatigue life of fixture screws in osseointegrated dental implants. Int J Oral Maxillofac Implants 1992;7:26-33

18 Wee AG, Cheng AC, Eskridge RN: Accuracy of 3 conceptually different die systems used for implant casts. J Prosthet Dent 2002;87:23-29

19 Taylor TD, Agar JR, Vogiatzi T: Implant prosthodontics: current perspective and future directions. Int J Oral Maxillofac Implants 2000;15:66-75

20 Goheen K, Vermilyea S, Vossoughi J, et al: Torque generated by handheld screwdrivers and mechanical torquing devices for osseointegrated implants. Int J Oral Maxillofac Implants 1994;9:149-155

21 Skalak R: Biomechanical considerations in osseointegrated prostheses. J Prosthet Dent 1983;49:843848

22 Binon P: Implants and components: entering the new millennium. Int J Oral Maxillofac Implants 2000;15:76-94

23 Cobb GW, Metcalf AM, Parsell D, et al: An alternate treatment method for a fixed - detachable hybrid prosthesis: a clinical report. J Prosthet Dent 2003;89:230-243

24 Tzenakis G, Nagy W, Fournelle R, et al: The effect of repeated torque and salivary contamination on the preload of slotted gold implant prosthetic screws. J Prosthet Dent 2002;88:183-191 